\title{
Backscattering Mössbauer MIMOS II and XRF studies on tektites from different strewn fields
}

\author{
B. F. O. Costa • G. Klingelhöfer • M. Panthöfer • \\ E. I. Alves
}

Published online: 18 December 2013

(C) Springer Science+Business Media Dordrecht 2013

\begin{abstract}
Room temperature ${ }^{57} \mathrm{Fe}$ Mössbauer spectroscopy has been used to obtain information on the redox and coordination of iron in tektites. A MIMOS II spectrometer in backscattering geometry has been used in the study, so that no sample preparation at all was required. X-ray fluorescence has been used to determine the composition of the tektites. Mössbauer spectra have been deconvoluted using three extended Voigtbased profiles to allow quantitative analysis of iron atoms valence and coordination. In all tektites, the $\mathrm{Fe}^{2+}$ sites have been distinguished in $\mathrm{Fe}$ with octahedral and tetrahedral coordination. The $\mathrm{Fe}^{2+}$ octahedral sites show a region of isomer shift (IS) and quadrupole splitting (QS), IS $=1.02-1.14 \mathrm{~mm} / \mathrm{s}$ and $\mathrm{QS}=1.82-2.12 \mathrm{~mm} / \mathrm{s}$, relative to $\alpha$-Fe. The $\mathrm{Fe}^{2+}$ tetrahedral sites show a region of hyperfine parameters of IS $=0.59-0.89 \mathrm{~mm} / \mathrm{s}$ and $\mathrm{QS}=1.14-1.60 \mathrm{~mm} / \mathrm{s}$. The $\mathrm{Fe}^{3+}$ sites show $\mathrm{IS}=0.11-$ $0.33 \mathrm{~mm} / \mathrm{s}$ and $\mathrm{QS}=0.02-0.04 \mathrm{~mm} / \mathrm{s}$. The $\mathrm{Fe}^{3+} / \mathrm{Fe}^{2+}$ ratio was found to be $0.025-0.149$.
\end{abstract}

Keywords Tektites $\cdot$ Natural glasses $\cdot$ Iron oxidation states $\cdot$ Silicic aluminosilicate melts

Proceedings of the 32nd International Conference on the Applications of the Mössbauer Effect (ICAME 2013) held in Opatija, Croatia, 1-6 September 2013

B. F. O. Costa $(\bowtie)$

CEMDRX, Physics Department, University of Coimbra, Rua Larga,

3004-516 Coimbra, Portugal

e-mail: benilde@ci.uc.pt

G. Klingelhöfer · M. Panthöfer

Institut für Anorganische und Analytische Chemie, Joh. Gutenberg-Universität Mainz,

55099 Mainz, Germany

E. I. Alves

Geophysical and Astronomical Observatory, Centre for Geophysics,

and Department of Earth Sciences, University of Coimbra, 3000-134 Coimbra, Portugal 


\section{Introduction}

Tektites are natural glasses originated from fused material spilled during a meteorite impact [1]. Tektites form several vast strewn fields on the Earth's surface. Four strewn fields are known: moldavites in Europe, around Moldavia, Czech Republic (the only ones that are light-green and translucent); bediasites and georgiaites in North America (Texas and Georgia, respectively); ivorites in Ivory Coast; tibetanites, chinites, indochinites, rizalites (from the Philippines), and australites, in the largest strewn field, which ranges from Tibet to the Antarctic Ocean [2].

Apart from the microtektites found in deep-sea sediments, tektites on land can be subdivided into three groups: splash-form tektites, aerodynamically ablated tektites, and Muong Nong-type tektites with irregular shapes and a layered structure. Some authors suggested that Muong Nong-type tektites probably have not travelled far from their location of origin, and may therefore be close to the impact crater [3, 4].

The melting of crystalline rocks by a meteorite impact leads to a highly non-equilibrium silicate melt. The redox reactions leading to equilibrium are primarily a function of temperature and oxygen fugacity imposed on the melt, and secondarily a function of the chemical composition of the melt itself. The knowledge of the $\mathrm{Fe}^{3+} / \mathrm{Fe}^{2+}$ ratios in tektites can provide information about their formation.

Mössbauer spectroscopy is one of the most powerful methods for determination of the iron atoms valence and coordination $[5,6]$.

A common feature observed in tektites is an anomalously low $\mathrm{Fe}^{3+} / \mathrm{Fe}^{2+}$ ratio [7] when compared with values of other silicate glasses, and this suggests that tektites were solidified in a low oxygen environment. There are evidence that Muong Nong-type tektites have a higher $\mathrm{Fe}^{3+} / \mathrm{Fe}^{2+}$ ratio than splash form tektites, a fact that is consistent with their morphology and the idea that solidification from the melt occurred at a lower temperature [8].

The oxygen partial pressure is presumably the most important factor in determining the $\mathrm{Fe}^{3+} / \mathrm{Fe}^{2+}$ ratio, although chemical composition, maximum temperature and heating/cooling histories cannot be ruled out as possible contributing factors.

Early in the investigations of tektites, chemical analysis has been mainly used for determination of oxidation state of iron. The results of that kind of analysis became controversial and unreliable [9]. Another reason for inaccurate measurements of the iron oxidation state is the sample preparation. Usually the samples are cut and ground in acetone or alcohol to prevent the contact with atmosphere. In our study we used backscattering geometry to collect Mössbauer spectra, with no need of sample preparation. We had already used this technique before to determine iron atoms valence and coordination in tektites from Thailand [10]. This method presents a big advantage relatively to the transmission geometry method found in literature, where the sample needs to be cut and crushed into powder, with possible changes in oxidation ratios.

In gamma ray- backscattering geometry method used in tektites, radiation penetration is about $400-500 \mu \mathrm{m}$, so that the surface, that oxidises readily, is the minor fraction of the tektite to be probed.

\section{Experimental procedure}

For the present work we have used Mössbauer spectroscopy to study Fe-site properties in a number sample of tektites from different strewn fields: moldavites, indochinites (including one Muong Nong type tektite), bediasites, chinites (including Guangdong tektites), 
rizalites and australites. Mössbauer spectra were recorded for all the samples at room temperature with a MIMOS II spectrometer [11] detecting $14.4 \mathrm{keV}$ radiation in backscattering mode, and a ${ }^{57} \mathrm{Co}(\mathrm{Rh})$ source with an activity of about $80 \mathrm{mCi}$. No sample preparation was done to carry out the measurements. The window of the detector, with a diameter of $15 \mathrm{~mm}$, is put directly against the sample, and the surface volume / total volume ratio of the probed tektite is about $2 \times 10^{-4} \%$. The fitting procedure of the spectra was carried out using a set of Voigt lines and parameters determined by least squares. The isomer shifts are given relative to $\alpha$-Fe at RT. X-ray fluorescence (XRF) measurements of pressed pellets (approx. $20 \mathrm{mg}$ sample diluted in $2 \mathrm{~g}$ boronic acid) were performed with a PANalytical aXios $4 \mathrm{~kW}$ instrument applying standardless methods as implemented in the SuperQ/OMNIAN V 5.0D program package (PANalytical B.V., Almelo, Netherlands (2009)).

\section{Results and discussion}

The compositions of the studied tektites from different strewn fields are listed in Table 1. The values obtained are in general accordance with literature. Ordinary tektites are typically composed of about $70 \mathrm{wt} \%$ silica. Bediasites, for instance, have very low $\mathrm{Mg}$ and $\mathrm{Ca}$, while moldavites are rich in $\mathrm{Si}$ and $\mathrm{K}$.

$\mathrm{X}$-ray diffraction, performed in all the samples, showed that they were amorphous.

Mössbauer spectroscopy was performed on all the samples. All spectra were deconvoluted using three extended Voigt based profiles to represent octahedrally coordinated $\mathrm{Fe}^{2+}$, tetrahedrally coordinated $\mathrm{Fe}^{2+}$, and $\mathrm{Fe}^{3+}$. This fitting method has already proved to be adequate in previous studies of oxidation states in Khon Kaen indochinites [10]. Also, other authors $[12,13]$ have proven this method useful to adjust the hyperfine parameters of glasses.

Many works dedicated to fit Mössbauer spectra of glasses, and tektites in particular, have focused on distributions with ad hoc correlations of isomer shifts and quadrupole splittings, being introduced to explain the asymmetries in the doublets. However, these complicated fitting methods underestimate the relative amount of $\mathrm{Fe}^{3+}$ in tektites, in many cases being a factor of 2-3 smaller than the results obtained by wet chemistry.

Typical room temperature ${ }^{57} \mathrm{Fe}$ Mössbauer spectra of the tektites are illustrated in Fig. 1, and their hyperfine parameters displayed in Table 2.

The Mössbauer spectra have a similar shape with only one apparent asymmetric doublet, a shape characteristic of glasses containing mainly ferrous iron. The absence of a sextuplet is due to the dilute character of the glasses and indicates the absence of magnetic phases. Broadening effects are important in glasses spectra with line-widths as large a $0.60 \mathrm{~mm} / \mathrm{s}$ against $0.30 \mathrm{~mm} / \mathrm{s}$ in crystals.

Mössbauer spectra have been used to estimate the fraction of each iron species in a structure giving rise to absorption, assuming that the peak area is directly proportional to the amount of iron in a site.

Our results show that variations in spectral parameters and $\mathrm{Fe}^{3+} / \mathrm{Fe}^{2+}$ ratios between strewn fields are more significant than variations between individuals or between locations within the same strewn field.

$\mathrm{Fe}^{3+} / \mathrm{Fe}^{2+}$ ratios for tektites, measured by various techniques, are $0.02-0.12$ [14]. The values obtained in this study are within this range. 
Table 1 Average major elements chemical composition (oxide wt $\%$ ) of the tektites studied, determined by $\mathrm{XRF}$

\begin{tabular}{lllllllll}
\hline & $\mathrm{SiO} 2$ & $\mathrm{~A} 12 \mathrm{O} 3$ & $\mathrm{Na} 2 \mathrm{O}$ & $\mathrm{Fe} 2 \mathrm{O} 3$ & $\mathrm{MgO}$ & $\mathrm{CaCO} 3$ & $\mathrm{~K} 2 \mathrm{O}$ & $\mathrm{TiO} 2$ \\
\hline Muong Nong & $70.12(1)$ & $18.45(9)$ & $2.79(4)$ & $2.52(2)$ & $2.94(3)$ & $1.42(2)$ & $1.25(1)$ & $0.40(2)$ \\
Thailandite & $70.53(2)$ & $17.17(1)$ & $3.02(3)$ & $2.74(3)$ & $2.90(2)$ & $1.62(1)$ & $1.62(2)$ & $0.31(2)$ \\
Rizalite & $71.09(2)$ & $15.67(2)$ & $2.74(1)$ & $2.34(1)$ & $2.34(1)$ & $3.63(1)$ & $1.55(1)$ & $0.32(2)$ \\
Chinite & $70.94(1)$ & $15.61(2)$ & $2.81(2)$ & $3.32(1)$ & $2.51(1)$ & $2.34(1)$ & $1.56(2)$ & $0.79(2)$ \\
Australite & $72.20(1)$ & $13.40(1)$ & $1.57(1)$ & $2.81(2)$ & $3.07(1)$ & $3.95(2)$ & $1.84(1)$ & $0.80(2)$ \\
Bediasite & $73.54(1)$ & $17.46(1)$ & $3.35(2)$ & $2.58(1)$ & $1.13(2)$ & $0.63(1)$ & $0.91(2)$ & $0.20(2)$ \\
Moldavite & $80.10(1)$ & $9.56(1)$ & $0.52(2)$ & $1.23(2)$ & $2.21(2)$ & $1.60(1)$ & $2.95(1)$ & $0.31(1)$ \\
\hline
\end{tabular}

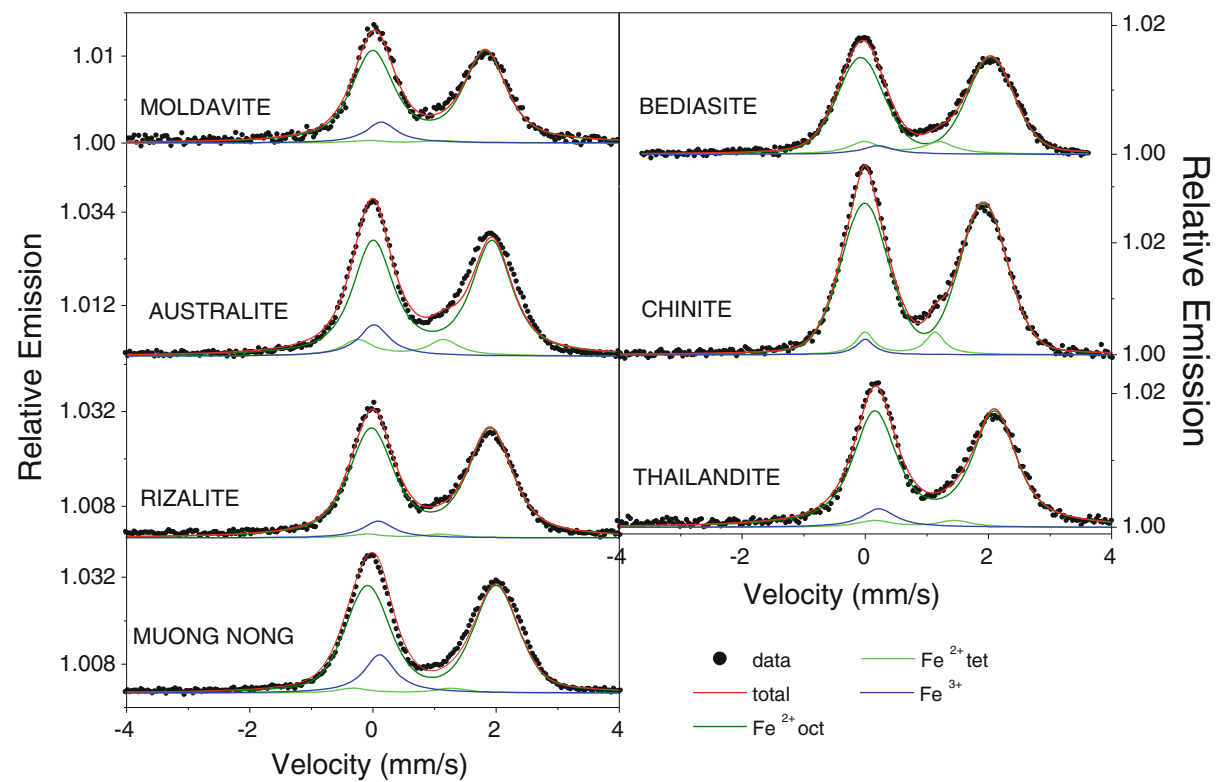

Fig. 1 Typical ${ }^{57} \mathrm{Fe}$ Mössbauer backscattering spectra representative of the tektites studied (Colour on line)

Changes in $\mathrm{Fe}^{3+} / \mathrm{Fe}^{2+}$ ratio during quenching of the melt correspond to an increase in the abundance of $\mathrm{Fe}^{3+}$ relative to $\mathrm{Fe}^{2+}$ which would require the absorption of oxygen at the surface of the sample from its environment.

The $\mathrm{Fe}^{3+} / \mathrm{Fe}^{2+}$ ratio observed in tektites is anomalously low compared with eg. terrestrial volcanic rocks, suggesting that they were solidified in a low oxygen environment such as high temperatures and reducing conditions.

Results show that the Guangdong (chinite) and Muong Nong tektites represent the two extremes in terms of $\mathrm{Fe}^{3+} / \mathrm{Fe}^{2+}$ ratio. Also, differences in the hyperfine parameters, mainly of the Muong Nong tektite compared with splash-form tektites, can be observed by Mössbauer measurements.

It has been observed for silicate glasses that the $\mathrm{Fe}^{3+} / \mathrm{Fe}^{2+}$ ratio decreases with decreasing $\mathrm{Ti} /(\mathrm{Ti}+\mathrm{Si})$ and $\mathrm{Al} /(\mathrm{Al}+\mathrm{Si})$ ratios [15]. In our study of tektites presented here, this is also generally the case, except for Muong Nong, Guangdong and moldavite tektites. One reason 
Table 2 Hyperfine parameters for $\mathrm{Fe}^{2+}$ and $\mathrm{Fe}^{3+}$ sites and ratios of site occupancies for the groups of tektites studied. IS given relative to $\alpha$-Fe

\begin{tabular}{|c|c|c|c|c|c|c|}
\hline & IS (mm/s) & $\mathrm{QS}(\mathrm{mm} / \mathrm{s})$ & WID $(\mathrm{mm} / \mathrm{s})$ & $\%$ & $\mathrm{Fe} 2+$ tetr $/ \mathrm{Fe} 2+\mathrm{oct}$ & $\mathrm{Fe} 3+/ \mathrm{Fe} 2+$ \\
\hline Muong Nong & & & & & 0.039 & 0.149 \\
\hline $\mathrm{Fe} 2+\mathrm{Oct}$ & $1.06(1)$ & 2.09(1) & $0.60(1)$ & 83.75 & & \\
\hline $\mathrm{Fe} 2+\mathrm{Tetr}$ & $0.59(1)$ & $1.60(1)$ & $0.60(1)$ & 3.25 & & \\
\hline $\mathrm{Fe} 3+$ & $0.22(1)$ & $0.02(1)$ & $0.60(1)$ & 13.0 & & \\
\hline Thailandite & & & & & 0.048 & 0.071 \\
\hline $\mathrm{Fe} 2+\mathrm{Oct}$ & $1.14(1)$ & $1.96(1)$ & $0.65(1)$ & 89.05 & & \\
\hline $\mathrm{Fe} 2+$ Tetr & $0.89(1)$ & $1.33(1)$ & $0.65(1)$ & 4.29 & & \\
\hline $\mathrm{Fe} 3+$ & $0.16(1)$ & $0.02(1)$ & $0.65(1)$ & 6.66 & & \\
\hline Rizalite & & & & & 0.027 & 0.060 \\
\hline $\mathrm{Fe} 2+\mathrm{Oct}$ & $1.05(1)$ & $1.93(1)$ & $0.60(1)$ & 91.85 & & \\
\hline $\mathrm{Fe} 2+$ Tetr & $0.61(1)$ & $1.20(1)$ & $0.60(1)$ & 2.50 & & \\
\hline $\mathrm{Fe} 3+$ & $0.20(1)$ & $0.01(1)$ & $0.60(1)$ & 5.65 & & \\
\hline Chinite & & & & & 0.080 & 0.025 \\
\hline $\mathrm{Fe} 2+\mathrm{Oct}$ & $1.07(1)$ & $1.93(1)$ & $0.60(1)$ & 90.40 & & \\
\hline $\mathrm{Fe} 2+\mathrm{Tetr}$ & $0.68(1)$ & $1.14(1)$ & $0.50(1)$ & 7.20 & & \\
\hline $\mathrm{Fe} 3+$ & $0.11(1)$ & $0.02(1)$ & $0.50(1)$ & 2.40 & & \\
\hline Australite & & & & & 0.119 & 0.104 \\
\hline $\mathrm{Fe} 2+\mathrm{Oct}$ & $1.07(1)$ & $1.93(1)$ & $0.60(1)$ & 80.92 & & \\
\hline $\mathrm{Fe} 2+\mathrm{Tetr}$ & $0.56(1)$ & $1.40(1)$ & $0.60(1)$ & 9.64 & & \\
\hline $\mathrm{Fe} 3+$ & $0.12(1)$ & $0.02(1)$ & $0.60(1)$ & 9.44 & & \\
\hline Bediasite & & & & & 0.110 & 0.035 \\
\hline $\mathrm{Fe} 2+\mathrm{Oct}$ & $1.09(1)$ & $2.12(1)$ & $0.60(1)$ & 87.01 & & \\
\hline $\mathrm{Fe} 2+\mathrm{Tetr}$ & $0.61(1)$ & $1.21(1)$ & $0.60(1)$ & 9.58 & & \\
\hline $\mathrm{Fe} 3+$ & $0.32(1)$ & $0.02(1)$ & $0.60(1)$ & 3.41 & & \\
\hline Moldavite & & & & & 0.023 & 0.093 \\
\hline $\mathrm{Fe} 2+\mathrm{Oct}$ & $1.02(1)$ & $1.83(1)$ & $0.60(1)$ & 89.47 & & \\
\hline $\mathrm{Fe} 2+\mathrm{Tetr}$ & $0.61(1)$ & $1.20(1)$ & $0.60(1)$ & 2.06 & & \\
\hline $\mathrm{Fe} 3+$ & $0.25(1)$ & $0.04(1)$ & $0.60(1)$ & 8.47 & & \\
\hline
\end{tabular}

can be that Muong Nong-type tektites have higher contents of volatile elements compared to splash-form tektites [16], which imply their lower temperature formation when compared to splash-form tektites. Also, analysis of moldavites shows evidence for volatile fractionation, but they also have variations in non-volatile elements that cannot be explained by removal of only the volatiles. Meisel et al. [17] suggest that variations in the source regions and removal of volatiles by subsequent weathering of tektites make the comparison of volatile elements with average upper crustal composition impossible. In our study we have not determined volatile elements, so we cannot confirm this explanation.

For each strewn field, the hyperfine parameters obtained in our study are consistent. The variations in spectral parameters between strewn fields are more significant than variations between individuals.

All the spectra have a strong quadrupole doublet with IS around $1 \mathrm{~mm} / \mathrm{s}$ and QS around $1.9 \mathrm{~mm} / \mathrm{s}$, which are typical parameters for $\mathrm{Fe}^{2+}$ in octahedral coordination in tektites. The 
exceptions are for Muong Nong-type tektites, bediasites and moldavites, which have QS of $2.09(1) \mathrm{mm} / \mathrm{s}, 2.12(1) \mathrm{mm} / \mathrm{s}$ and $1.83(1) \mathrm{mm} / \mathrm{s}$, respectively. These values are in accordance with other studies $[18,19]$. The higher values of QS are characteristic of some silicate glasses, alkali silicate glasses, basaltic glasses and phosphate glasses, while lower values of QS show in Lipari obsidians [19].

The doublet corresponding to $\mathrm{Fe}^{2+}$ in tetrahedral coordination is not always seen in spectra of tektites. However, some authors have seen it already, eg [19-21]. Rossano and Dunlap obtained IS and QS values around $0.6 \mathrm{~mm} / \mathrm{s}$ and $1 \mathrm{~mm} / \mathrm{s}$, respectively, for different tektites. Some of our values approach the ones obtained in other natural glasses in which QS usually ranges between 1.4 and $1.8 \mathrm{~mm} / \mathrm{s}$ [22].

The hyperfine values obtained for $\mathrm{Fe}^{3+}$ show some differences between different strewn fields, but are in good agreement with the values referred in literature for tektites.

It is worth mentioning that the present study obtains $\mathrm{Fe}^{3+}$ amounts that are closer to wet chemistry amount values [23].

The complex fitting methods using ad hoc IS-QS correlations, introduced to explain asymmetries in the doublets, may mask the true $\mathrm{Fe}^{3+}$ content. Our fitting method uses a subspectrum for $\mathrm{Fe}^{3+}$ component to explain the observed asymmetry in the spectra. We think that the use of gamma-ray backscattering geometry method gives a reliable measurement of the iron valence in the tektites, as the tektite is probed mainly in the bulk. The surface, that oxidises more readily than the bulk, is only about $2 \times 10^{-4} \%$ of the total probed sample.

An example of using distributions of hyperfine parameters in the analysis of Mössbauer spectra of tektites, measured in transmission geometry and using either powder or thin sections obtained from the tektites samples is the work of Dunlap et al. [20]. In their work, the $\mathrm{Fe}^{3+}$ content in the Muong Nong tektite is $45 \%$ of total Fe, whereas our study gives for our Muong Nong tektite sample $13 \%$ (Table 2). Another example is the $\mathrm{Fe}^{3+} / \mathrm{Fe}^{2+}$ ratio of $0.006-0.003$ obtained by Dunlap et al. for the Thailandite tektite whereas our study gives 0.071 for the same ratio, and for our Thailandite tektite.

\section{Conclusions}

Mössbauer spectroscopy has been used to investigate the local Fe environment in tektites from different strewn fields. The spectra have been deconvoluted using Voigt-based functions to represent octahedrally coordinated $\mathrm{Fe}^{2+}$, tetrahedrally coordinated $\mathrm{Fe}^{2+}$, and $\mathrm{Fe}^{3+}$. The distinction between tetrahedral and octahedral components of the $\mathrm{Fe}^{2+}$ sites is consistent with other analysis using distributions parameters and analysis of spectra of glasses synthesized from silicate rocks with compositions close to the ones of tektites. The variations in spectral parameters and $\mathrm{Fe}^{3+} / \mathrm{Fe}^{2+}$ ratios between strewn fields are more significant than variations between individuals or between locations within the same strewn field. The $\mathrm{Fe}^{3+} / \mathrm{Fe}^{2+}$ ratio was found to be $0.025-0.149$. The use of gamma ray backscattering geometry method seems to be adequate to the study, as no sample preparation is needed and the surface volume/ total volume ratio of the probed tektite is very small.

Acknowledgments This work was supported from funds from FEDER (Programa Operacional Factores de Competitividade COMPETE) and from FCT - Fundação para a Ciência e Tecnologia under the project PEst-C/FIC/UI0036/2011. B.F.O. Costa also gratefully acknowledges the DAAD grant received for a Study Visit in Joh. Gutenberg-Universität Mainz from December 2012 to March 2013. The authors also want to thank a referee for useful suggestions. 


\section{References}

1. Koeberl, C.: Geol. Soc. Am. Spec. Pap. 239, 133-151 (1994)

2. O'Keefe, J.A.: Tektites and their origin. NASA Goddard Space Flight Center (1975)

3. McCall, G.J.M.: Tektites in the Geological Record: Showers of Glass from the Sky. The Geological Society, London (2001)

4. Koebert, C.: Geochim. Cosmochim. Acta 56, 1033 (1992)

5. Thorpe, A.N., et al.: JGR 99, 10881-10885 (1994)

6. Orkasson, N., Helgasson, O., Sigurdsson, H.: Geol. Soc. Am. Spec. Pap. 307, 445-452 (1996)

7. Chao, E.C.T.: The Petrographic and chemical characteristics of tektites. In: O'Keefe, J.A. (ed) Tektites, p. 51. University of Chicago, Chicago (1963)

8. Son, T.H., Koeberl, C.: Met. Planet. Sci 46(6), 805-815 (2005)

9. Volovetsky, M.V., Rusakov, V.S., Chistyakova, N.I., Lukanin, O.A.: Hyp. Inter. 186, 83-88 (2008)

10. Costa, B.F.O., Klingelhöher, G., Alves, E.I.: Hyp. Inter. 224, 51-56 (2014)

11. Klingelhöfer, G., et al: JGR 108(8067), 8.1-8.17 (2003)

12. Hammant, O.M., Forder, S.D., Bingham, P.A., Hand, R.J.: Hyp. Inter 192, 37-42 (2009)

13. Forder, S.D., Hannant, O.M., Bingham, P.A., Hand, R.J.: J. Phys. Conf. Ser. 217, 012072 (2010)

14. Lukanin, O.A., Kadik, A.A.: Geochem. Inter. 45, 857-881 (2007)

15. Mysen, B.O., Virgo, D.: Am. Miner. 74, 58-76 (1989)

16. Melosh, H.J.: Meteorit. Planet. Sci. 33(4 Suppl), A104 (1998)

17. Meisel, T., et al.: Meteorit. Planet. Sci. 32, 493-502 (1997)

18. Dunlap, R.A., Eelman, D.A., MacKay, G.R.: J. Non-Cryst. Solids 223, 141-146 (1998)

19. Rossano, S., Balan, E., Morin, G., Bauer, J.-P., Calas, G., Brouder, C.: Phys. Chem. Miner. 26, 530-538 (1999)

20. Dunlap, R.A., Sibley, A.D.E.: J. Non-Cryst. Solids 337, 36-41 (2004)

21. Dunlap, R.A.: Hyp. Inter. 110, 217-225 (1997)

22. Dickson, B.L., Smith, G.: Can. Miner. 14, 206-215 (1976)

23. Fudali, R.F., Dyar, M.D., Griscom, D.L., Schreiber, H.D.: Geochim. Cosmochim. Acta 51, 2749-2756 (1987) 